\title{
Diel movements of fishes linked to benthic seascape structure in a Caribbean coral reef ecosystem
}

\author{
Steven Hitt ${ }^{1,2}$, Simon J. Pittman ${ }^{1,2, *}$, Richard S. Nemeth ${ }^{2}$ \\ ${ }^{1}$ National Oceanic \& Atmospheric Administration, Biogeography Branch, 1305 East-West Highway, Silver Spring, \\ Maryland 20910, USA \\ ${ }^{2}$ University of the Virgin Islands, Center for Marine and Environmental Studies, 2 John Brewers Bay, St. Thomas, \\ US Virgin Islands 00802, USA
}

\begin{abstract}
Many common fishes associated with Caribbean coral reef ecosystems use resources from more than 1 patch type during routine daily foraging activities. Few studies have provided direct evidence of connectivity across seascapes, and the importance of benthic seascape structure on movement behavior is poorly known. To address this knowledge gap, we coupled hydro-acoustic technology to track fish with seafloor mapping and pattern analysis techniques from landscape ecology to quantify seascape structure. Bluestriped grunts Haemulon sciurus and schoolmaster snapper Lutjanus apodus were tracked over $24 \mathrm{~h}$ periods using boat-based acoustic telemetry. Movement pathways, and day and night activity spaces were mapped using geographical information system (GIS) tools, and seafloor structure within activity spaces was mapped from high-resolution aerial photography and quantified using spatial pattern metrics. For both fish species, night activity spaces were significantly larger than day activity spaces. Fish exhibited a daytime preference for seascapes with aggregate coral reef and colonized bedrock, then shifted to night activity spaces with lowercomplexity soft sediment including sand, seagrass, and scattered coral/rock. Movement path complexity was negatively correlated with seascape complexity. This demonstrates direct connectivity across multiple patch types and represents the first study to apply quantitative landscape ecology techniques to examine the movement ecology of marine fish. The spatially explicit approach facilitates understanding to the linkages between biological processes and the heterogeneity of the landscape. Such studies are essential for identifying ecologically relevant spatial scales, delineating essential fish habitat and designing marine protected areas.
\end{abstract}

KEY WORDS: Seascape ecology $\cdot$ Spatial pattern $\cdot$ Acoustic tracking $\cdot$ Home range $\cdot$ Fish movements

Resale or republication not permitted without written consent of the publisher

\section{INTRODUCTION}

Coral reef ecosystems typically exist as mosaics of patch types (i.e. coral reefs, seagrasses, sand, mangroves) exhibiting complex spatial patterns in biophysical structure. Many common species of fish connect multiple patch types through routine daily foraging movements, ontogenetic shifts, and seasonal and spawning migrations (Parrish 1989, Chapman \& Kramer 2000, Pittman \& McAlpine 2003). Diel migration, a widespread phenomenon for fish such as grunts and snappers, links adjacent patch types that are used for different purposes (e.g. foraging and refuge; Ogden \& Buckman 1973,
Parrish 1989, Krumme 2009). Routine migratory movements are thought to optimize survival by maximizing growth rate and minimizing risk from predation by preferential utilization of areas that provide suitable food and refuge (Dahlgren \& Eggleston 2000).

Our knowledge of fish movements across the seascape has come primarily from underwater visual observations (Friedlander \& Parrish 1998, Nagelkerken et al. 2000, Mumby et al. 2004), from extractive net and trap sampling (e.g. Beets \& Friedlander 1998, Halpin 2000, Hammerschlag \& Serafy 2010), and chemical isotope signatures (Kieckbusch et al. 2004, Nagelkerken \& van der Velde 2004). Such techniques, 
however, provide only low-resolution reconstructions of movement pathways (stable isotopes) or indirect evidence of connectivity inferred from spatial distribution patterns of different life stages or size classes (Gillanders et al. 2003). Furthermore, conventional fish distribution studies are usually restricted to daytime sampling, often conducted at arbitrary spatial scales, and are typically subject to a range of geographical and temporal biases in sampling design (Pittman \& McAlpine 2003). Manual acoustic tracking of fish movements combined with high-resolution global positioning system (GPS) technology provides a direct measure of individual fish movement pathways and space-use patterns over time that is not restricted to daylight hours (Holland et al. 1996, Lowe et al. 2003, Topping et al. 2005).

An additional knowledge gap exists in the linking of fish movement behavior to the underlying benthic seascape structure. Landscape ecology, the study of the ecological consequences of spatial patterning, provides an appropriate conceptual and analytical framework for examining fish-seascape relationships for highly mobile species (Robbins \& Bell 1994, Pittman et al. 2004). In terrestrial landscape ecology, movement behavior has long been recognized as an important link between process and pattern (Lima \& Zollner 1996, McIntyre \& Wiens 1999). It is now becoming apparent that the spatial patterning of the benthic seascape, such as the spatial arrangement of patches, the size and shape of patches, and edges influence the distribution of fish and ecological processes such as movement, growth, and predator-prey relationships (Irlandi \& Crawford 1997, Pittman et al. 2004, GroberDunsmore et al. 2009, Boström et al. 2011, this issue, Kendall et al. 2011, this issue). Conventional ecological studies, however, rarely quantify benthic structure at spatial scales broad enough to encompass even the routine daily space use patterns of the organisms of interest (Pittman \& McAlpine 2003).

Advances in geographical information system (GIS) tools have improved our ability to quantify space use patterns in marine animals and the structure of the seascape over which they traverse (Pittman \& McAlpine 2003). Although great progress has been made in the field of movement ecology, marine studies have not considered the influence of the spatially explicit patterning of the benthic seascape on movement and habitat utilization patterns (Lima \& Zollner 1996). We propose that by combining spatially explicit movement studies with quantitative landscape ecology, a more complete understanding of species-habitat relationships and seascape connectivity can be developed.

We applied a novel approach to movement ecology in the marine environment through the coupling of concepts and quantitative tools from landscape eco- logy, together with conventional hydro-acoustic tracking techniques and habitat mapping from remote sensing. We demonstrate how seascape structure can be quantified at functionally relevant spatial scales, as determined by the space use patterns of the organisms of interest. Multiple individuals of 2 ecologically important fish species with widespread occurrence across the Caribbean region, bluestriped grunt Haemulon sciurus and schoolmaster snapper Lutjanus apodus, were acoustically tracked throughout their diel cycle $(24 \mathrm{~h})$. These fish are important carnivores that rest in areas with sufficient structural complexity to provide daytime refuge (e.g. large branching corals, patch reefs, boulders) and then migrate to seagrass beds for nocturnal foraging on benthic invertebrates and small fishes (Ogden \& Ehrlich 1977, Burke 1995, Cocheret de la Morinière et al. 2003a,b). Such movements are considered to be key vectors for the cross-boundary transfer of energy and nutrients (Clark et al. 2009) and facilitate coral and seagrass growth through nutrient flux (e.g. Meyer et al. 1983, Meyer \& Schultz 1985, Layman et al. 2011). Despite their ecological importance, the detailed diel space use patterns and the scheduling of daily activities, such as diel migrations, remain poorly understood.

The primary hypotheses regarding the influence of seascape structure on diel movement patterns of Haemulon sciurus and Lutjanus apodus include: (1) If foraging takes place at night and resting during the day, then activity spaces will be larger and more complex in shape at night than during the day. (2) If seagrass patches are important as nocturnal foraging areas, then fish should spend a larger proportion of the night over seagrass when compared to other available patch types. (3) If day and night activity spaces are used for different functions, then we expect the composition and spatial configuration of the seascape including size and shape to differ in day versus night areas. (4) In more spatially heterogeneous seascapes, the movement path of individual fish is expected to be more convoluted or tortuous, reflecting more complex individual navigational decisions in response to spatially varying seafloor structure.

\section{MATERIALS AND METHODS}

Study sites. Fish were acoustically tracked between July 2008 and March 2010 at 2 locations in the US Virgin Islands: Great Lameshur Bay, St. John, and Brewer's Bay, St. Thomas (Fig. 1). Great Lameshur Bay is located on the southeastern coast of St. John within the Virgin Islands National Park. The interior of Great Lameshur Bay $\left(18^{\circ} 18^{\prime} 54^{\prime \prime} \mathrm{N}, 64^{\circ} 43^{\prime} 23^{\prime \prime} \mathrm{W}\right)$ is dominated by 2 seagrass species (Syringodium filiforme and 


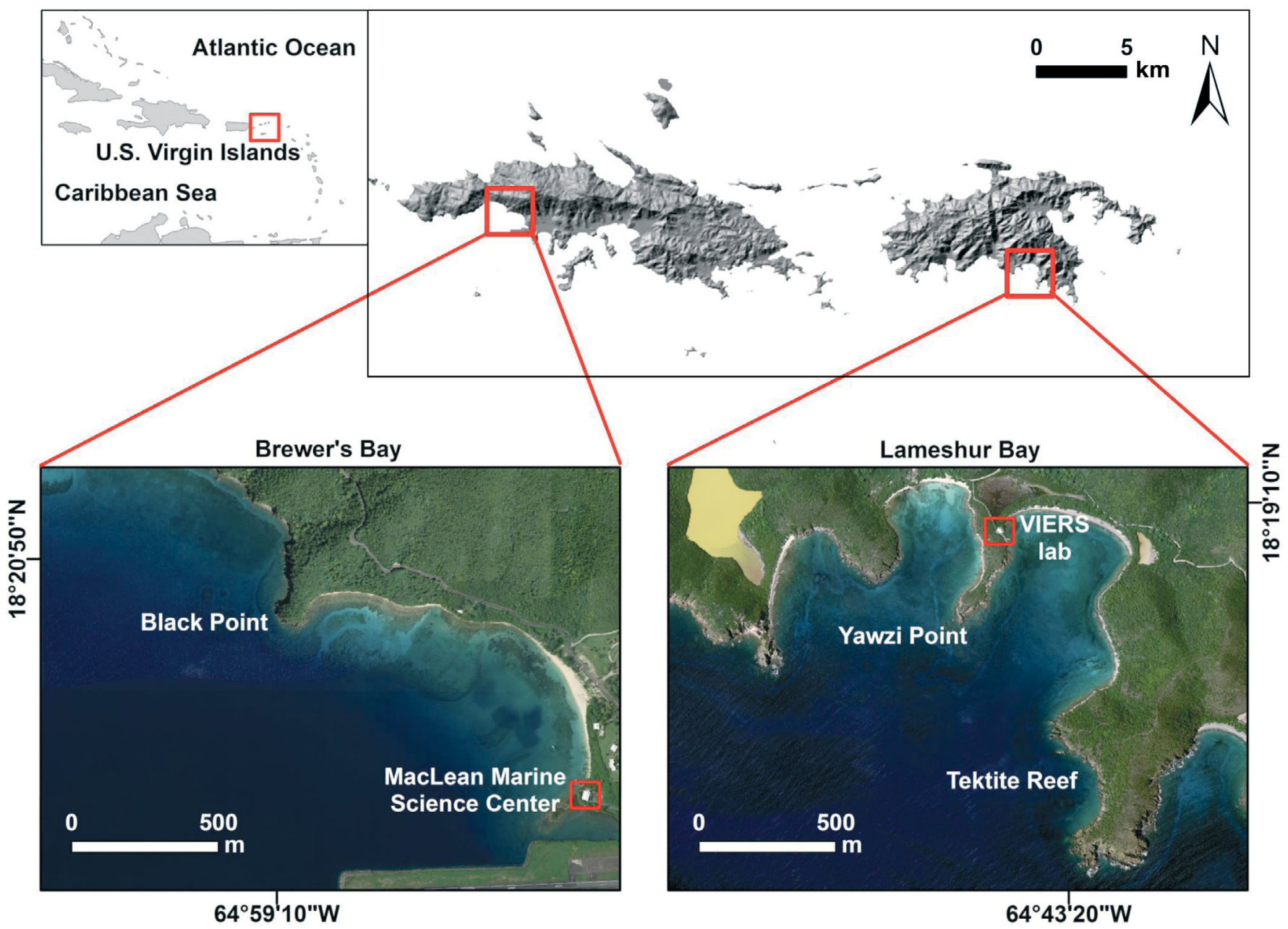

Fig. 1. Study locations for fish tracking within the US Virgin Islands; Brewer's Bay (left) and Lameshur Bay (right)

Thalassia testudinum) and is bordered along the northern and eastern shoreline by extensive fields of small $\left(<4 \mathrm{~m}^{2}\right)$ boulders and cobblestones. Much larger $\left(\geq 4 \mathrm{~m}^{2}\right)$ submerged and semi-submerged boulders can also be found around southwestern and southeastern promontories and are typically colonized by sponges, gorgonians (Gorgonia ventalina, Pseudoplexaura spp., Plexaurella spp.), hard corals (Millepora alcicornis, Porites astreoides, Montastraea annularis), and the endangered elkhorn coral Acropora palmata. Fringing coral reefs on the southeastern (Tektite Reef) and southwestern (Yawzi Point) coasts are dominated by M. annularis (Fig. 1). A nearly contiguous sand zone (3 to $10 \mathrm{~m}$ width) circles the bay and separates the seagrasses interior to the bay from adjacent patches of fringing reef. Brewer's Bay $\left(18^{\circ} 20^{\prime} 34^{\prime \prime} \mathrm{N}\right.$, $64^{\circ} 58^{\prime} 51^{\prime \prime} \mathrm{W}$ ) is located on the southwestern coast of St. Thomas. Brewer's Bay also has interior seagrass beds, small boulder and cobblestone fields, large boulders surrounding a promontory (Black Point), and M. annularis-dominated fringing coral reefs (Fig. 1).
Tagging and tracking. A total of 6 individuals of each target fish species, Haemulon sciurus and Lutjanus apodus, were obtained using baited fish traps set for $48 \mathrm{~h}$ on sandy patches adjacent $(<5 \mathrm{~m})$ to benthic structures near their daytime resting locations (i.e. patch reefs, boulders). Each specimen ( $>24 \mathrm{~cm}$ total length, TL) had a V9-2L continuously 'pinging' acoustic transmitter with $1 \mathrm{~s}$ ping rate (dimensions $9 \times 29 \mathrm{~mm}$,

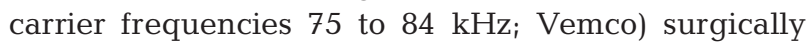
implanted into its abdominal cavity. Fish were kept in flow-through seawater holding tanks at either the MacLean Marine Science Center (St. Thomas) or the Virgin Islands Environmental Resource Station (VIERS) laboratory (St. John) until they exhibited normal behavior (i.e. freely swimming), which was typically within $2 \mathrm{~h}$ of surgery. Tagged fish were then transported in aerated containers to the site of capture and released by a snorkeler to ensure safe descent to the substratum.

Continuous tracking methodologies (e.g. Lowe et al. 2003, Topping et al. 2005, Papastamatiou et al. 2009) were used to quantify diel movement behavior and 
habitat utilization patterns. Tracking began no earlier than $24 \mathrm{~h}$ post tag implantation to allow fish to re-acclimate to the habitat and to minimize the effects of surgery on movement behavior (Papastamatiou et al. 2009). All continuous tracking was conducted for an interval of $24 \mathrm{~h}$ from a 17 foot motorized catamaran equipped with a directional hydrophone (Vemco model VH110) and acoustic receiver (Vemco model VR100). Prior to the study, the range $(\sim 200 \mathrm{~m})$ and accuracy ( 2 to $5 \mathrm{~m}$ ) of the hydrophone were tested in each bay. A researcher manually operated the hydrophone, which allowed for $180^{\circ}$ tilting and $360^{\circ}$ rotation and hastened transmitter signal acquisition. GPS fixes were acquired at 15 min intervals using a hand-held GPS. Fixes were only taken when the transmitter signal strength was repeatedly greater than $85 \%$ while the hydrophone was pointed facing directly downward below the vessel (i.e. perpendicular to the substrate).

Quantifying activity spaces and movement paths. All activity space estimations were performed using the ABODE extension (Laver 2005) in ArcMap GIS v. 9.2 (ESRI). A $95 \%$ kernel utilization distribution (KUD) was calculated from GPS fixes acquired for each fish during diurnal and nocturnal periods that spanned $24 \mathrm{~h}$. The KUD is a probability distribution that represents the area in which a fish can be found $95 \%$ of the time during the tracking event. Here the 95\% KUD was only calculated for the diurnal and nocturnal time periods to make specific diel movement comparisons (e.g. Tolimieri et al. 2009). Diurnal and nocturnal periods were defined based on the United States Naval Observatory sunrise/sunset time charts (http://aa.usno. navy.mil/data/docs/RS_OneYear.php) for Charlotte Amalie (St. Thomas) and Coral Bay (St. John), whereby night began at sunset and day began at sunrise.

Measures of tortuosity were analyzed for diurnal and nocturnal movement pathways of each fish using estimates of the fractal dimension $(D)$, as described by Nams (2005) and Papastamatiou et al. (2009). The fractal dimension of a movement path is a measure of the convolutedness of a movement pathway and typically varies between 1 (straight line) and 2 (patch completely covers a plane). Recent work has raised concerns about calculating overall $D$ values for movement paths that are correlated random walks (i.e. when the overall movement path is random but successive points are correlated; Nams \& Bourgeois 2004, Papastamatiou et al. 2009). Therefore, we used Fractal version 5.0 to compare the movement paths and their mean fractal $D$ values across multiple spatial scales, and then calculated the fractal mean only for paths that deviated significantly from a correlated random walk (CRW) model. Fractal v. 5.0 detects deviations from a CRW model by calculating observed and expected (generated by CRW model) net distance traveled values for each movement path and then calculates the mean difference between them (see Nams \& Bourgeois 2004).

Mapping and quantifying seascape structure. Benthic habitat maps with a minimum mapping unit of $4 \mathrm{~m}^{2}$ were hand digitized from aerial photography (ground resolution $0.3 \times 0.3 \mathrm{~m}$ ) of St. Thomas and St. John using the Habitat Digitizer Extension in ArcGIS 9.3 (Kendall et al. 2001); 9 patch types-aggregate coral reef, colonized bedrock, colonized boulder, patch coral reef (individual), rocky reef, sand, sparse seagrass with 10-30\% cover, dense seagrass with 30-90\% cover, and scattered coral/rock in unconsolidated sediment (SCR)-were classified from the aerial photography. Colonized substrates were sparsely covered with a variety of scleractinian corals, gorgonians, and sponges. Since little is known about the appropriateness of a single thematic resolution when mapping seascapes for ecological studies, we used a hierarchical scheme to allow for selection of 2 levels of thematic resolution (i.e. a detailed and a coarse benthic habitat map) to quantify seascape structure (Pittman et al. 2004, Kendall \& Miller 2008). The detailed thematic resolution benthic habitat map was created using all 9 patch types, and coarse map was created using only 3 patch types: (1) hardbottom (all types of reef, pavement, and boulder combined), (2) sand (including $\mathrm{SCR}$ ), and (3) seagrasses.

Benthic map accuracy. To assess and validate the accuracy of the benthic habitat maps, reference points ( $n=204$ ) were randomly generated on each map according to an area-weighted, stratified random sampling protocol using the GIS-based NOAA Sampling Design Tool (Menza 2008). Reference points were located in the field with a handheld GPS receiver, the patch type was independently evaluated by a snorkeler, and underwater photographs were taken for additional verification. For final accuracy assessment, we compared the benthic habitat map reference point data to in situ data by constructing an error matrix for each map to show overall accuracy (the sum of correct classifications, divided by the total number of reference points), producer's accuracy (percentage of correct classifications per patch type), and user's accuracy (percentage of correctly classified points divided by the number of validation points per patch type). The Tau coefficient $\left(\mathrm{T}_{\mathrm{e}}\right)$ was used to measure the improvement of classification accuracy compared to a random assignment of map units to map categories (Ma \& Redmond 1995).

For the detailed benthic habitat map with 9 patch types, the overall accuracy of the Lameshur Bay and Brewer's Bay maps was 89.2 and $78.4 \%$, respectively; however, the user's accuracy for sparse seagrasses (10-30\% cover) was 50\% for the Lameshur Bay map due to difficulty differentiating between sparse sea- 
grass and sand. Map accuracies for the coarser benthic habitat maps with 3 patch types were $95.1 \%$ for Lameshur Bay and 91.2\% for Brewer's Bay.

Because coarse versions of the maps with only 3 patch types (hard bottom, sand, and seagrass) improved overall map accuracies, all but 2 spatial pattern metrics were applied to the more accurate coarser-resolution map. The detailed map with all 9 patch types, however, was used to examine fish residency times within patch types and to calculate patch richness within activity spaces. Patch richness is the number of patch types within day and night activity spaces. Polygons representing day and night activity spaces were overlayed on the benthic habitat maps, and used to clip out the seascapes using a GIS tool. Spatial pattern metrics were applied to the seascapes using Patch Analyst 4 extension (Elkie et al. 1999) for ArcGIS 9.3 and FRAGSTATS (McGarigal et al. 2002). Metrics included the area of each patch type, the number of patch types (i.e. patch richness), the shape index, and edge metrics such as total edge and contrast-weighted edge density. Raster data were used to calculate the shape index, which equals the patch perimeter (number of raster cells) divided by the minimum perimeter (number of raster cells) possible for a maximally compact patch (square raster format) of the corresponding patch area (McGarigal et al. 2002). Contrast-weighted edge density is a measure of patch edge per unit area proportionate to the degree of contrast in the seascape (McGarigal et al. 2002).

Statistical analysis. Paired $t$-tests were used to examine the statistical difference between day and night movement path complexity, activity space size, activity space shape index, patch richness, and seascape. Data were $\log _{10}$ or fourth-root transformed to meet the parametric assumptions of normality; $D$ was $\log (D-1)$ trans- formed (sensu Nams 2005). To test whether movement path complexity was positively correlated with seascape complexity, we used linear regressions to compare the fractal $D$ values to total edge, contrastweighted edge density, patch type area, and patch richness of the seascape. To measure similarities between the multivariate seascape structure of day and night activity spaces and to test for significant differences, non-parametric, multivariate analyses were conducted in PRIMER 6 (Clarke \& Gorley 2006). Multivariate data were fourth-root transformed to allow intermediate and low values to make a contribution (Clarke \& Green 1988) and were averaged across time period (i.e. day and night) and species. Ordination by non-metric multidimensional scaling (nMDS) was applied to matrices of Bray-Curtis pairwise similarities (Clarke et al. 2006) to examine between-sample patterns of seascape structure in a 2-dimensional plot. Analysis of similarity (ANOSIM; Clarke \& Green 1988, Clarke 1993) was used to test for significant differences in multivariate seascape structure within and among Haemulon sciurus and Lutjanus apodus day and night activity spaces. We used similarity percentage analysis (SIMPER, Clarke 1993) to identify the seascape metrics contributing most to differences in the seascape structure.

\section{RESULTS}

\section{Fish activity spaces}

Adult Haemulon sciurus and Lutjanus apodus were tracked for $24 \mathrm{~h}$ between July 2008 and March 2010 (Table 1). All fish except H1 exhibited increased night movement activity that resulted in either an expansion

Table 1. Haemulon sciurus and Lutjanus apodus. Summary data of 6 H. sciurus (H1-H6) and 6 L. apodus (L1-L6) tracked in Great Lameshur and Brewer's Bays, US Virgin Islands, between July 2008 and March 2010. The ratio between night (N) and day (D) activity space areas calculates the magnitude of the difference between the 2 activity spaces. Activity space areas are calculated from rasterized polygons of $95 \%$ fixed kernel utilization distribution estimates. Distance between day and night activity spaces is calculated as the Euclidean distance between the centroid of each activity space. TL: total length; dates are given as m/d/y

\begin{tabular}{|c|c|c|c|c|c|c|c|c|}
\hline ID & $\begin{array}{c}\mathrm{TL} \\
(\mathrm{cm})\end{array}$ & $\begin{array}{c}\text { Tag } \\
\text { frequency }(\mathrm{kHz})\end{array}$ & Tag date & Track date & $\begin{array}{l}\text { Distance } \\
\text { D to N (m) }\end{array}$ & $\begin{array}{l}\text { Day area } \\
\qquad\left(\mathrm{m}^{2}\right)\end{array}$ & $\begin{array}{l}\text { Night area } \\
\left(\mathrm{m}^{2}\right)\end{array}$ & $\begin{array}{l}\text { Ratio } \\
\text { (N/D) }\end{array}$ \\
\hline H1 & 24.5 & 84 & $7 / 13 / 2008$ & $7 / 14 / 2008$ & 70.2 & 12487 & 8836 & 0.7 \\
\hline $\mathrm{H} 2$ & 29.7 & 78 & $10 / 9 / 2008$ & $10 / 23 / 20080$ & 2.4 & 281 & 609 & 2.2 \\
\hline H3 & 29.5 & 81 & $6 / 2 / 2009$ & 6/4/2009 & 187.6 & 175 & 12621 & 72.1 \\
\hline $\mathrm{H} 4$ & 30.6 & 75 & 8/1/2009 & $8 / 26 / 2009$ & 332.7 & 283 & 15663 & 55.3 \\
\hline H5 & 29.3 & 78 & $9 / 16 / 2009$ & $9 / 30 / 2009$ & 171.8 & 764 & 4861 & 6.4 \\
\hline H6 & 29.0 & 78 & $3 / 25 / 2010$ & $4 / 6 / 2010$ & 329.6 & 2678 & 25267 & 9.4 \\
\hline L1 & 38.3 & 78 & $1 / 8 / 2009$ & $1 / 13 / 2009$ & 9.5 & 332 & 2651 & 8.0 \\
\hline L2 & 29.5 & 84 & 4/9/2009 & $4 / 22 / 2009$ & 11.0 & 627 & 2859 & 4.6 \\
\hline L3 & 30.1 & 78 & $6 / 2 / 2009$ & $6 / 11 / 2009$ & 485.7 & 1700 & 19459 & 11.4 \\
\hline L4 & 33.1 & 84 & 8/1/2009 & 9/2/2009 & 360.2 & 4277 & 19187 & 4.5 \\
\hline L5 & 25.1 & 63 & $12 / 9 / 2009$ & $12 / 14 / 20090$ & 277.9 & 163 & 9062 & 55.6 \\
\hline L6 & 31.0 & 75 & $1 / 2 / 2010$ & $1 / 9 / 2010$ & 52.7 & 644 & 6482 & 10.1 \\
\hline
\end{tabular}


of the day activity space or a re-location to a new night activity space via a nocturnal migration. As a result, the size and shape of day and night activity spaces varied widely among all individuals (Table 1, Figs. 2-4); 8 of the 12 diurnal activity space areas recorded for $H$. sciurus and L. apodus were smaller than $800 \mathrm{~m}^{2}$ (mean $\pm \mathrm{SE}: 2034 \pm 1016 \mathrm{~m}^{2}$ ), whereas all but 1 of the 12 nocturnal activity space areas was larger than $2600 \mathrm{~m}^{2}$ $\left(10630 \pm 2262 \mathrm{~m}^{2}\right.$; Table 1). For both H. sciurus and $L$. apodus, the mean area of night activity spaces was significantly greater than the mean area of day activity spaces (H. sciurus: $t=-2.90, \mathrm{p}=0.034 ;$ L apodus: $t=$ $-6.12, \mathrm{p}=0.002)$, thus hypothesis $H_{1}$ was accepted (Table 2). There was no significant difference between $H$. sciurus and $L$. apodus mean activity space area when day and night activity spaces were combined $(t=$ $0.0684, \mathrm{p}=0.946$ ). There also was no significant difference between the shape of day and night activity spaces for either species (H. sciurus: $t=0.232, \mathrm{p}=$ 0.826 ; L. apodus: $t=-2.485, \mathrm{p}=0.056)$, indicating that the shape complexity between day and night activity spaces did not change significantly. In addition to complexity, the shapes of activity spaces tended to be elongated and generally encompassed a distinctive highcontrast edge between patch types such as hardbottom and softbottom areas. Day and night spaces were geographically separated. The average distance between the centroids of day and night activity spaces was highly variable, ranging from 2.4 to $332 \mathrm{~m}$ (182.4 \pm $54.6 \mathrm{~m})$ for $H$. sciurus and 9.5 and $485.7 \mathrm{~m} \mathrm{(199.5 \pm}$ $83.1 \mathrm{~m}$ ) for $L$. apodus (Table 1).

\section{Haemulon sciurus seascape use}

For H. sciurus, the number of patch types (patch richness) within night activity spaces was not significantly different from day activity spaces $(t=-2.33, \mathrm{p}=0.067)$. The area of dense seagrasses (30-90\% cover), colonized bedrock, and sand was significantly greater in night than day activity spaces, and aggregate coral reef area was greater in day than night activity spaces (Fig. 5A,B). Day residence time for $H$. sciurus was highest in aggregate coral reef, followed by colonized bedrock, sand, and dense seagrasses (Fig. 5A). Despite having low areal cover in day and night activity spaces, colonized bedrock was the second-most used patch type during the day (Fig. 5A) and the most used at night (Fig. 5B). Furthermore, the second-highest residence time recorded for $H$. sciurus at night was in seagrass, which encompassed the largest proportion of most night activity spaces (Fig. 5B). Use of aggregate coral reefs decreased more than $55 \%$ at night, while use of colonized bedrock and dense seagrasses increased more than $10 \%$ at night (Fig. 6A).

\section{Lutjanus apodus seascape use}

In contrast to Haemulon sciurus, patch richness was significantly higher in $L$. apodus night activity spaces than in day activity spaces $(t=-3.50, \mathrm{p}=0.017)$. All 9 patch types had greater areas in the night activity spaces than in the day activity spaces (Fig. 5C,D). During the day, L. apodus demonstrated habitat utilization patterns that were similar to those of $H$. sciurus; their highest residence times were recorded in hardbottom patch types, such as colonized boulder, aggregate coral reef, and sand (Fig. 5C). At night, L. apodus residence times were highest in sand, aggregate coral reef, colonized boulder, and colonized bedrock patch types, respectively (Fig. 5D). From day to night, residence times decreased most in colonized boulder patch types and increased by more than $15 \%$ in sand (Fig. 6B). During the day, 3 patch types were used by both species (i.e. aggregate reef, colonized bedrock, and sand), although average aggregate coral reef and sand areas in L. apodus activity spaces were more than $50 \%$ less than those found in H. sciurus activity spaces (Fig. 5A,C). Average colonized bedrock area in $L$. apodus diurnal activity spaces was twice that of $H$. sciurus (Fig. 5A,C). Six patch types had greater areas within night activity spaces of $L$. apodus than in $H$. sciurus night activity spaces (Fig. 5B,D). Residence time in seagrasses was significantly higher at night, but only when combining the 2 species. Thus, $H_{2}$ was accepted only for both species combined and was rejected for individual species due to inter-species variability in habitat utilization patterns (Table 2).

\section{Similarity of day and night seascapes}

For Lutjanus apodus, day and night seascapes were structurally similar (average similarity $=89 \%$ ), with moderate separation between groups and no statistically significant difference detected (ANOSIM R $=0.41, \mathrm{p}>$ 0.05). At the level of individual patch types the use of sand patches was greater in the night than within day seascapes, and notably, seagrasses were absent from day seascapes and present (albeit relatively small areas) in night seascapes. For Haemulon sciurus, day and night seascapes were structurally more dissimilar (average similarity $=65 \%$ ) than for L. apodus, but high overlap between groups was measured, resulting in no significant difference $(R=0.28, p>0.05)$. The greatest contribution to dissimilarity was the markedly higher average area of sand and seagrasses frequented by fish in night seascapes, accounting for $61 \%$ of the dissimilarity. Hardbottom area and total edge contributed 20.0 and $16.3 \%$, respectively, and patch richness contributed least $(<1.8 \%)$ to the group differences, with a similar number of patch types observed in day and night seascapes for both species. 

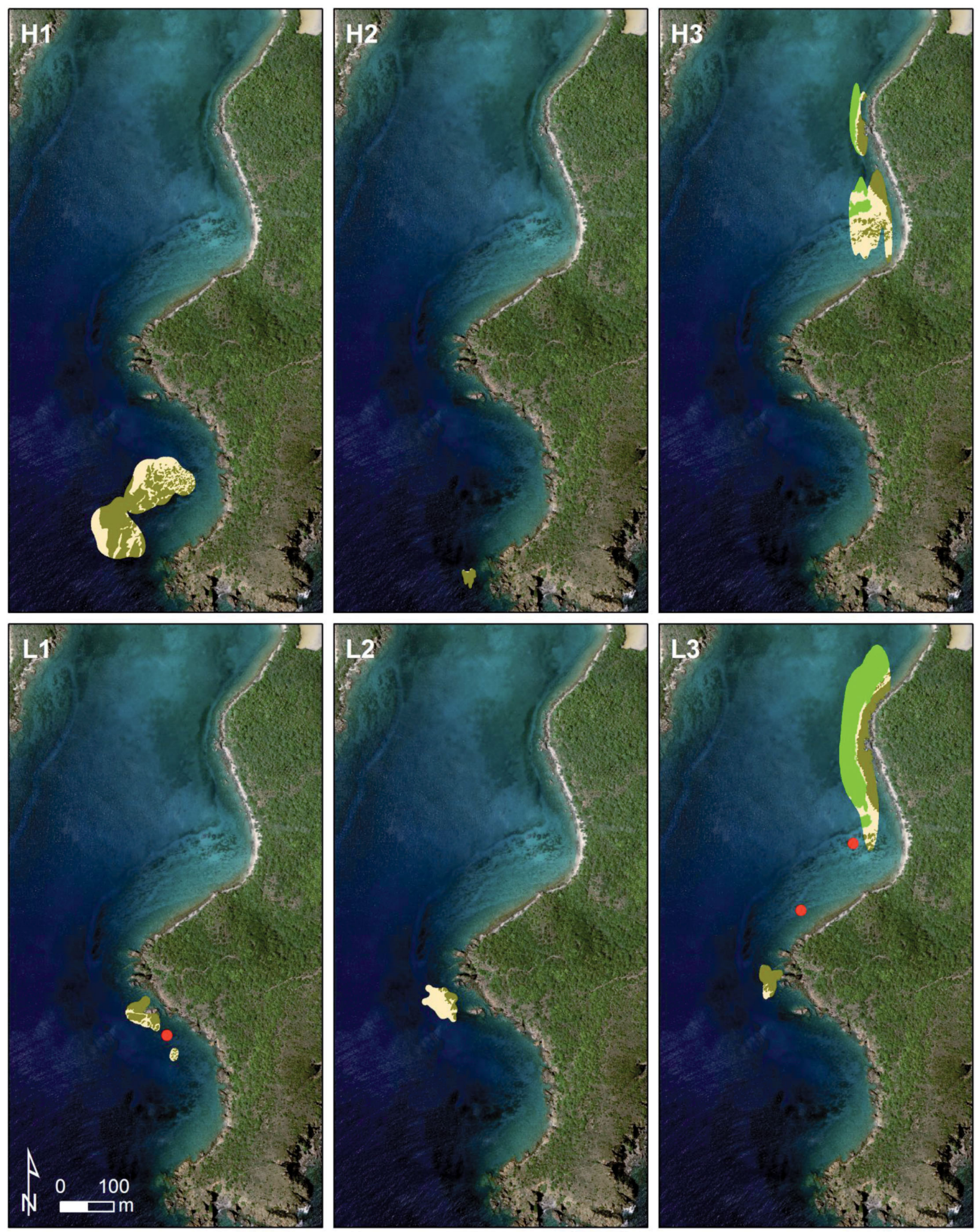

Hard bottom

Sand

\section{Seagrass}

Fig. 2. Haemulon sciurus and Lutjanus apodus. $95 \%$ kernel utilization distribution diurnal and nocturnal activity space estimates for H. sciurus (H1-H3) and L. apodus (L1-L3) tracked in Lameshur Bay, St. John. The red dots represent points acquired during the migration between day and night activity spaces 

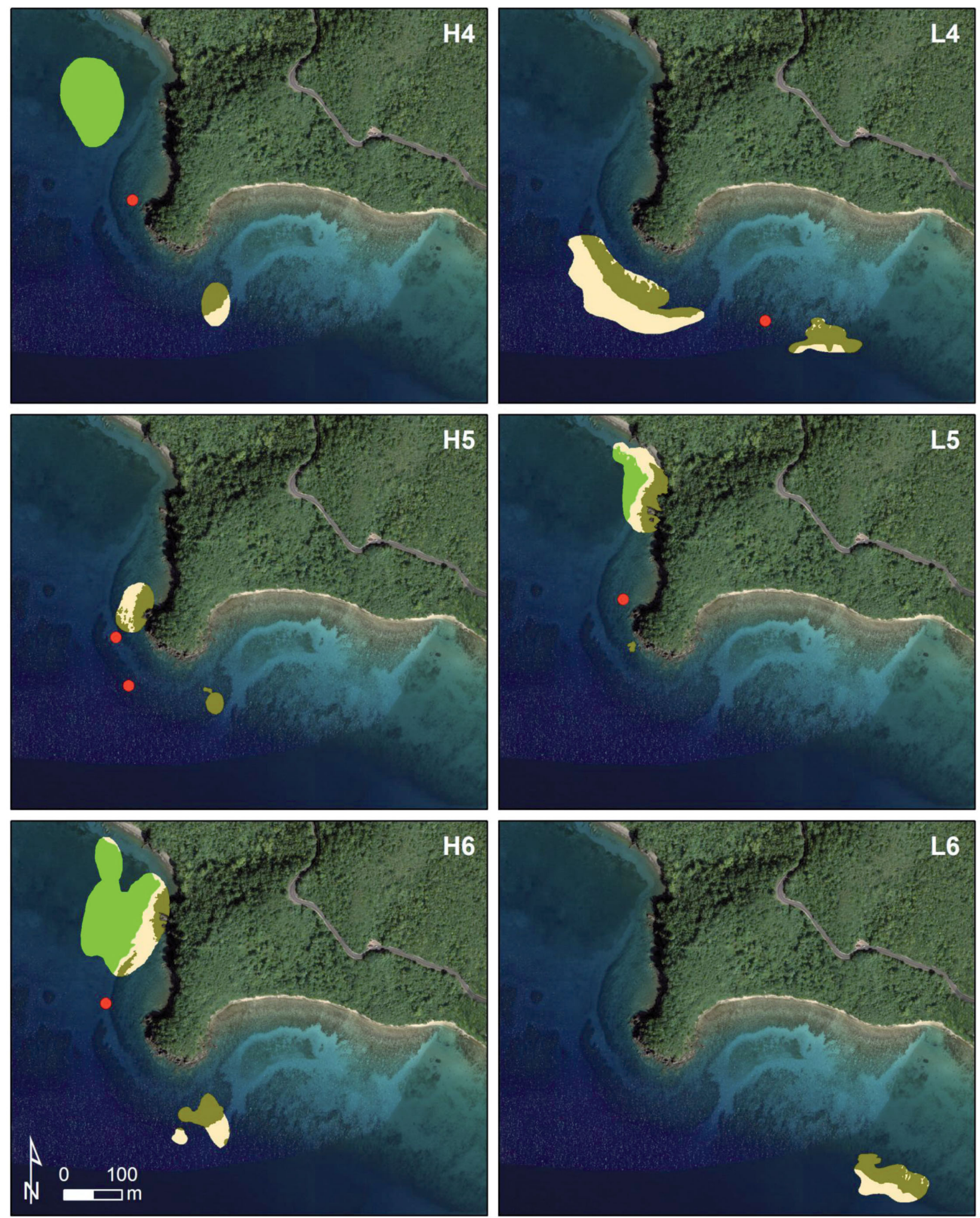

\section{Hard bottom}

Sand

Seagrass

Fig. 3. Haemulon sciurus and Lutjanus apodus. $95 \%$ kernel utilization distribution diurnal and nocturnal activity space estimates for H. sciurus (H4-H6) and L. apodus (L4-L6) tracked in Brewer's Bay, St. Thomas. The red dots represent points acquired during the migration between day and night activity spaces 


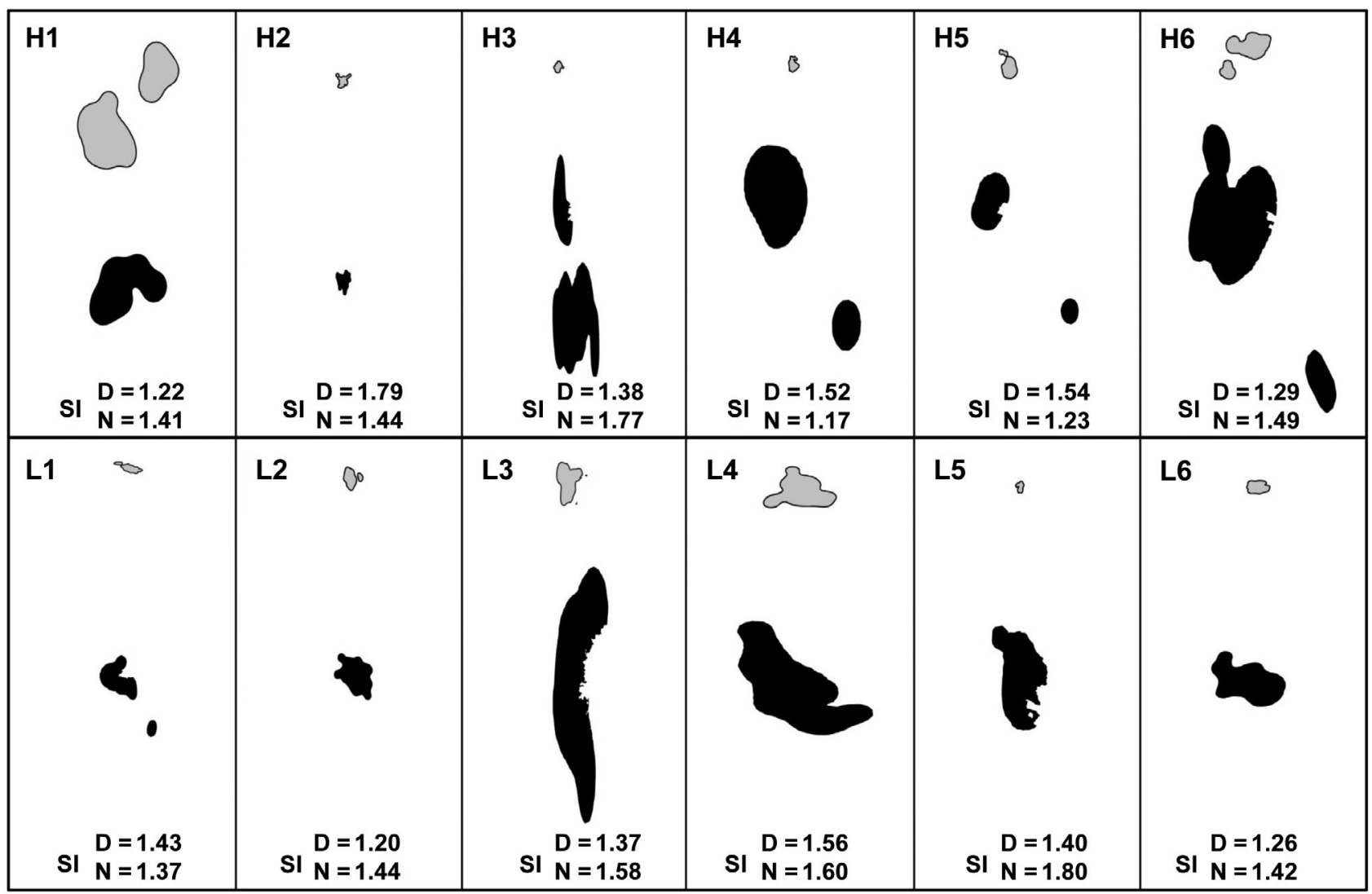

Fig. 4. Haemulon sciurus and Lutjanus apodus. Shape of day (gray) and night (black) activity spaces for H. sciurus (H1-H6) and L. apodus (L1-L6). SI: shape index values for day (D) and night (N). All activity spaces are projected at the same scale

Table 2. Haemulon sciurus and Lutjanus apodus. Interpretation of the results of hypothesis testing for relationships between day and night activity spaces, movement behavior and seascape characteristics. Alternative hypotheses were accepted or rejected based on statistical significance $(\mathrm{p}<0.05)$

\begin{tabular}{|lll|}
\hline Hypothesis & Test result & Results statement \\
\hline $\begin{array}{l}H_{1} \text { : Night activity spaces are significantly } \\
\text { larger than diurnal activity spaces }\end{array}$ & Accepted & $\begin{array}{l}\text { Both } H \text {. sciurus and } L \text {. apodus night activity spaces were } \\
\text { significantly larger than day activity spaces }\end{array}$ \\
$\begin{array}{l}H_{2} \text { : Residence time in seagrasses is signifi- } \\
\text { cantly higher at night than during the day }\end{array}$ & $\begin{array}{l}\text { Only accepted } \\
\text { when species } \\
\text { were combined }\end{array}$ & $\begin{array}{l}\text { Combined residence time of } H \text {. sciurus and } L \text {. apodus in } \\
\text { seagrasses was significantly higher at night than during } \\
\text { the day }\end{array}$ \\
$\begin{array}{l}H_{3} \text { : Seascape structure is significantly } \\
\text { different between day and night activity } \\
\text { spaces }\end{array}$ & Rejected & $\begin{array}{l}\text { Seascape structures of day and night activity spaces were } \\
\text { not significantly different for } \text { H. sciurus and } L \text {. apodus }\end{array}$ \\
$\begin{array}{l}H_{4} \text { : Complexity of the movement paths is } \\
\text { positively correlated with seascape com- } \\
\text { plexity (i.e. patch richness, total edge, and } \\
\text { contrast-weighted edge density) }\end{array}$ & Rejected & $\begin{array}{l}\text { Movement path complexity was negatively correlated with } \\
\text { total edge and area of hardbottom and sand for } H . \text { sciurus } \\
\text { and } L \text {. apodus. Movement path complexity was negatively } \\
\text { correlated with patch richness for } H \text {. sciurus only }\end{array}$ \\
\hline
\end{tabular}

\section{Structural differences between multivariate seascape types}

Following hierarchical cluster analysis of seascape metrics, 3 groups (A, B, C) were clearly identified based on $75 \%$ dissimilarity in multivariate seascape structure.
Two-dimensional nMDS ordination plots offered a very good representation of the similarity between seascapes with low stress values and were used to characterize seascape types with high within-group similarity (Fig. 7). Heterogeneity was lowest in Seascape A, highest in Seascape B, and somewhat variable in 
Seascape C (Fig. 7). Seascape A was characterized by smaller activity spaces, lower patch richness, total edge, hard bottom, and sand area, and very little seagrass area. The low heterogeneity habitat of Seascape A was primarily day activity spaces (Fig. 7), with fish undergoing relatively tortuous movement pathways ( $D \geq 1.53)$; the 8 largest $D$ values recorded were in Seascape A. Highest heterogeneity Seascape B habitat exhibited the highest occurrence of seagrasses. Differences in activity space area, patch richness, total edge, and area of sand contributed to Seascape B's dissimilarity from A and C. Seascape B was comprised entirely of night activity spaces (Fig. 7). Seascape C represented an intermediate seascape type with moderate heterogeneity defined by intermediate sized day and night activity spaces. Fish used hardbottom habitat and patchy sand with no seagrasses present, but a high density of edges, particularly edges with high contrast between adjacent patch types (i.e. sand-reef interface).

\section{Path complexity-seascape relationships}

Comparisons between mean fractal $D$ and seascape structure were restricted to 22 samples where movement paths deviated significantly from a CRW model.

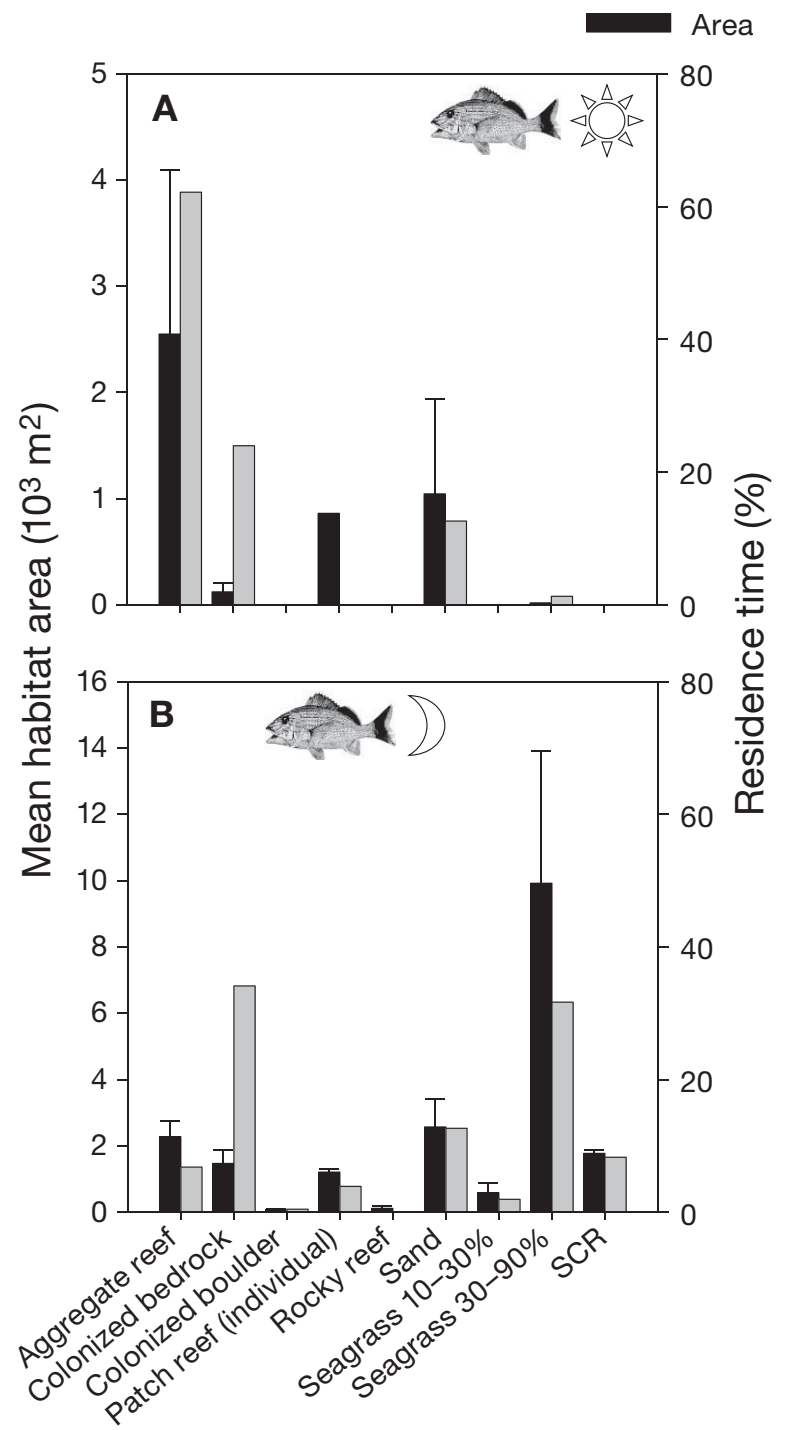

\section{Residence}

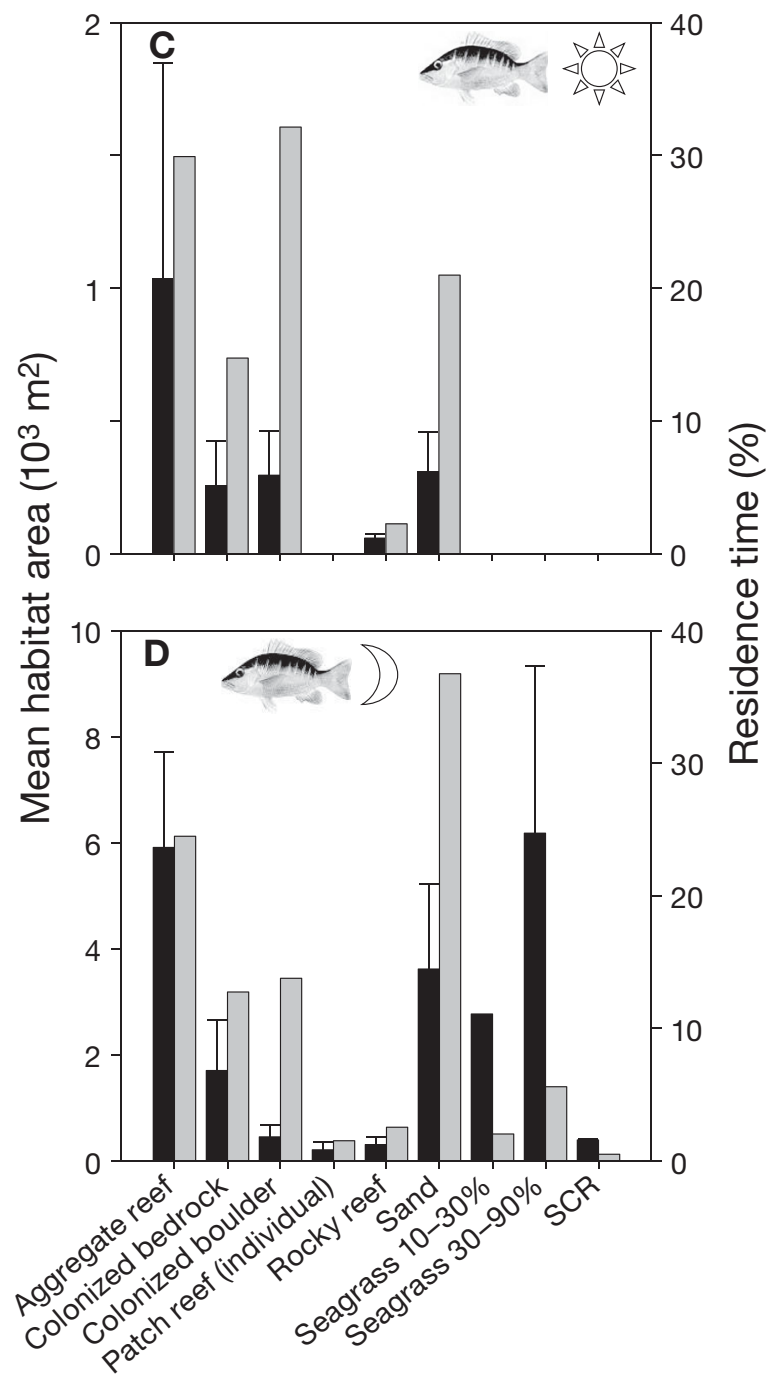

Fig. 5. Haemulon sciurus and Lutjanus apodus. Plot of residence time $(\%)$ and mean patch type area $\left(\mathrm{m}^{2}\right)$ of aggregate coral reef, colonized boulder, colonized bedrock, individual patch reef, rocky reef, sand, scattered coral/rocks in unconsolidated sediment (SCR), sparse seagrasses (10-30\% cover), and dense seagrasses (30-90\% cover) used by 6 H. sciurus (A, B) and 6 L. apodus (C, D) in their day and night activity spaces. Note: $y$-axis scales differ between day and night activity spaces. Error bars absent from area columns with single data points. Error bars: \pm SEM 

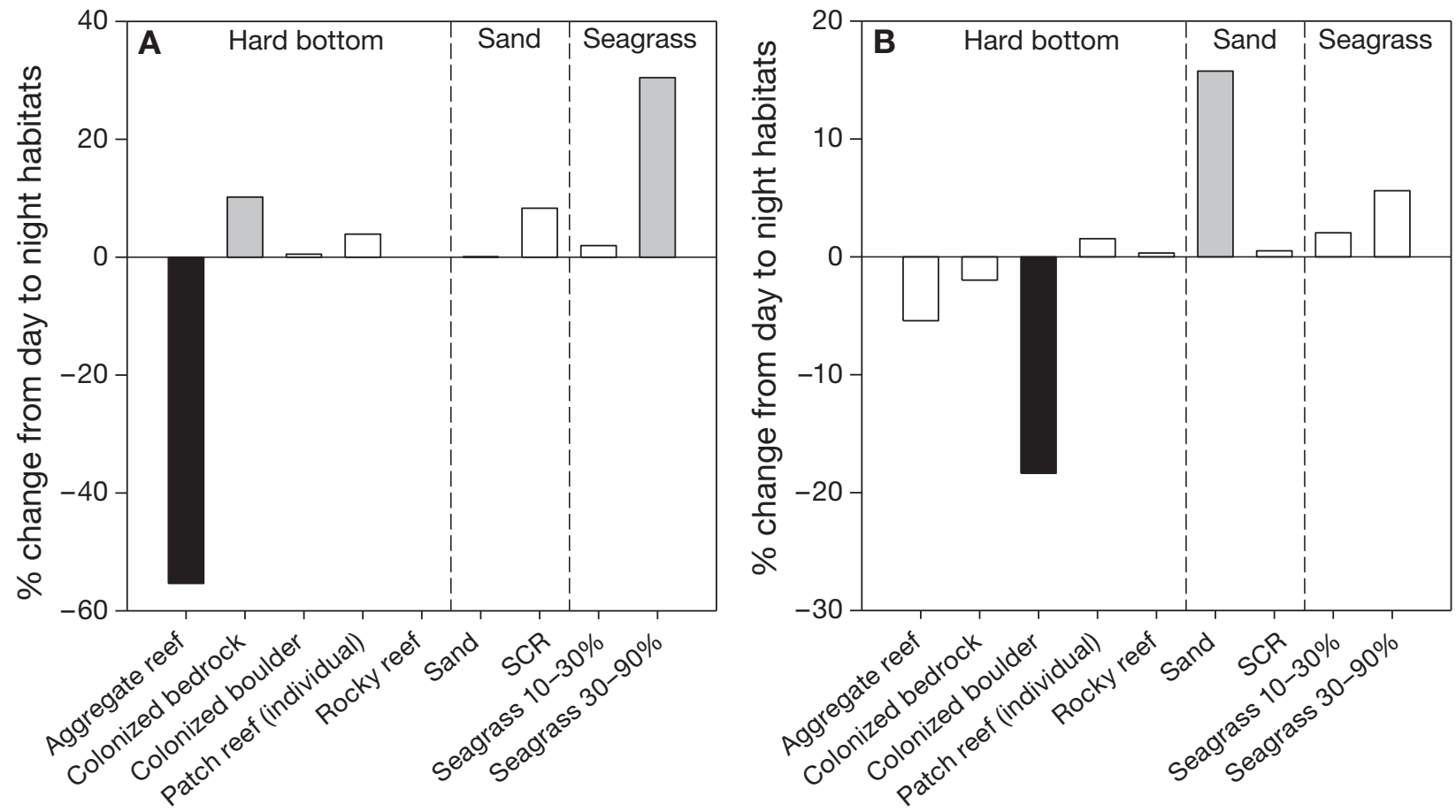

Fig. 6. Haemulon sciurus and Lutjanus apodus. Percent change of residence times for patch types within day and night activity spaces for: (A) H. sciurus and (B) L. apodus. Black bars indicate $>10 \%$ decrease in residence time, gray bars indicate $>10 \%$ increase in residence time, and white bars indicate $<10 \%$ change in residence time. Patch types are grouped into 3 coarse categories (hardbottom, sand, seagrass) for comparison. SCR: scattered coral/rocks in unconsolidated sediment

For the entire diel cycle (day and night combined), there was no significant difference in path complexity $(t=-0.058, \mathrm{p}=0.95)$ between Haemulon sciurus and Lutjanus apodus. Mean $D$ was relatively high for both species (H. sciurus: $1.78 \pm 0.18 ;$ L. apodus: $1.70 \pm 0.11$ ), indicating very convoluted or tortuous movement patterns. Day movement paths were significantly more tortuous than night movement paths for both species (H. sciurus: $t=-8.30, \mathrm{p}=0.0037$; L. apodus: $t=-3.37$, $\mathrm{p}=0.0199)$. Of the 22 mean $D$ values analyzed, the 8 most tortuous ( $D \geq 1.84$, e.g. Fig. $8 \mathrm{~A})$ paths occurred during the day and the 7 least tortuous $(D \leq 1.36$, e.g. Fig. 8B) paths occurred at night.

Linear regressions between path complexity $(D)$ and 5 individual pattern metrics revealed negative linear relationships for 27 of 30 bivariate regressions, of which 8 were strong (Table 3) and statistically significant negative relationships. Stronger relationships were detected across the entire diel activity space (day and night seascapes combined). Overall, relatively low heterogeneity seascapes, with greater area of hardbottom and sand patches, relatively low edge (i.e. large continuous patches), and low to medium patch richness, were navigated by more complex fish movement pathways. Hypothesis $H_{4}$, which predicted more complex pathways across more complex seascapes, was rejected at the spatial and thematic resolution of our study (Table 2). More specifically, the path complexity of Haemulon sciurus decreased as total edge, hardbottom area, sand area, and patch richness increased, with slightly stronger linear relationships modeled for night activity (Table 3). Similar relationships (although less strong) emerged for Lutjanus apodus, with the strongest negative linear relationships for path complexity and area of hardbottom benthic classes (Table 3). Area of seagrasses was excluded from the linear regression analysis due to a high proportion of 0 values in the data.

\section{DISCUSSION}

In our diel movement study, we found that both grunts and snappers move across spatially heterogeneous patch mosaics through routine daily movements that encompass seascapes over 100's of $\mathrm{m}^{2}$. These benthic seascapes represent an important component of the ecological neighborhood quantified at the level of the individual (sensu Addicott et al. 1989). We provide direct evidence of both inter-species and intra-species variability in space use patterns, including the size and shape of activity spaces. Species differences are likely to be determined by species specific life-history traits, predation pressure, competitors and dietary requirements. In addition, individualistic differences may reflect organism ex- 
perience, condition, and behavior. Similarly, acoustic tracking of 2 snapper species in the Bahamas found substantial fine-scale intra-population variability in movement patterns (Hammerschlag-Peyer \& Layman 2010). Although the movement patterns in our study varied among individuals, our results demonstrated that both fish species shared similar sun-synchronous scheduling of diel migrations and some similarities in generalized habitat utilization patterns. As in terrestrial fauna (Bolnick et al. 2003), we suggest that intra-population variation is not rare in marine fish and can have a significant effect on ecological processes and therefore caution is required before such complexities are simplified in favor of broad generalizations, which can lead to sub-optimal decisions and uncertain results in conservation planning and ecosystem-based fisheries management. Our study represents an important first step towards applying a landscape ecology approach to behavioral marine ecology that will increase our understanding of marine animal movements across heterogeneous seascapes. Based on our knowledge of the multi-habitat use patterns of coral reef associated fish and the spatial scales at which fish use their environment, we advocate a shift in perspective from the study of individual patch types (e.g. seagrass beds or coral reefs) to a focus on determining how fish use and respond to seascape mosaics.

\section{Diel behavior patterns and seascape use}

The scheduling of migration behavior was closely tied to sunset and sunrise, a phenomenon also described for French grunts Haemulon flavolineatum, white grunts $H$. plumierii, and other species (McFarland et al. 1979,
Dorenbosch et al. 2004, Krumme 2009). H. sciurus and Lutjanus apodus departed daytime resting areas at sunset and returned from nighttime feeding areas at sunrise. Although direct evidence of foraging activity during nighttime tracking periods was not obtained, other studies suggest that these 2 species feed primarily at night (Rooker \& Dennis 1991, Clark et al. 2009, Hammerschlag et al. 2010). As hypothesized, night activity spaces of $H$. sciurus and $L$. apodus were significantly larger than day activity spaces. Maximum night activity spaces of $25267 \mathrm{~m}^{2}$ and $19459 \mathrm{~m}^{2}$ for $H$. sciurus and $L$. apodus were 70 and 11 times greater than their corresponding day activity spaces. Maximum distances between the centers of day and night activity spaces were $332 \mathrm{~m}$ for $H$. sciurus and $485 \mathrm{~m}$ for $L$. apodus. Other studies have reported similar scales of movement; for instance, Beets et al. (2003) and Verweij \& Nagelkerken (2007) observed H. sciurus and L. apodus moving estimated distances of 230 to $767 \mathrm{~m}$ from day resting areas to nighttime foraging areas. Thus, day and night activity spaces and combined diel activity spaces provide an ecologically meaningful unit for scaling the environment in habitat-use studies (Pittman \& McAlpine 2003).

Haemulon sciurus and Lutjanus apodus had broadly similar seascape utilization patterns, generally showing a shift from high relief hardbottom habitats (i.e. coral and rocky reef and boulders) in the day to low relief softbottom habitats (i.e. sand and seagrasses) at night. During night excursions, both species used many more habitats than during the day. Habitat utilization patterns for H. sciurus in Brewer's and Lameshur Bays corroborated generalities from previous studies which highlighted the importance of seagrasses for nocturnal foraging in grunts (Ogden \& Ehrlich 1977, Burke 1995,

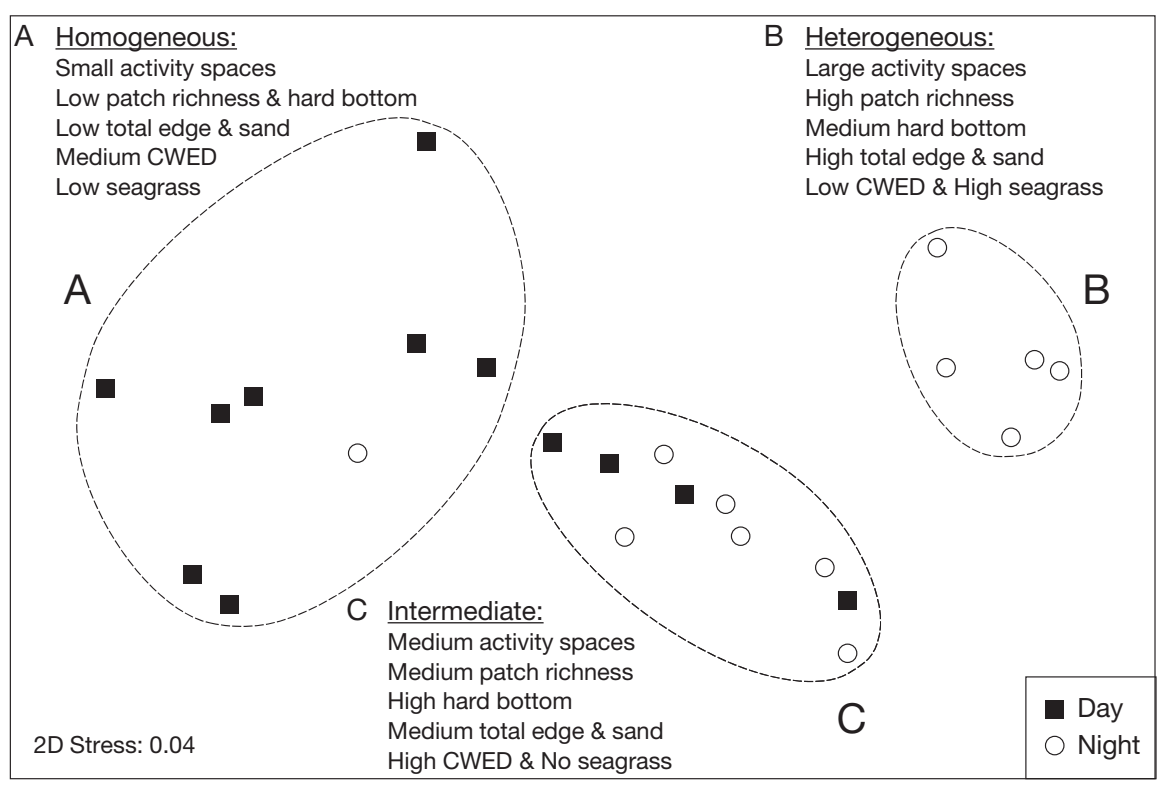

Fig. 7. Dissimilarity among diurnal and nocturnal activity spaces using non-metric multidimensional scaling plots (nMDS) showing relative dissimilarity in seascape composition (area of hardbottom, sand, and seagrass, patch richness) and configuration (total edge, contrast weighted edge density, CWED) for all samples. Hierarchical cluster analysis identified 3 cluster groups (i.e. seascape types A-C) based upon $75 \%$ dissimilarity 


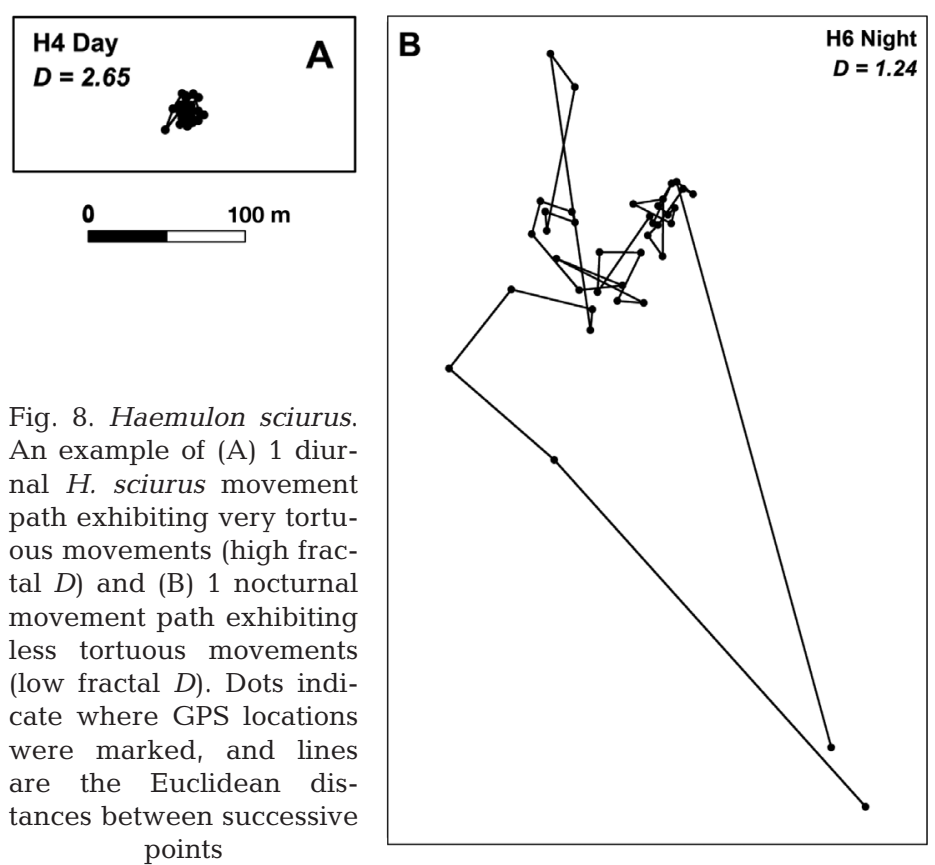

Table 3. Haemulon sciurus and Lutjanus apodus. Linear regressions between diurnal and nocturnal seascape metrics (total edge, contrast weighted edge density [CWED], hard bottom area, sand area, and patch richness) and the response variable (mean fractal $D$ ) for $H$. sciurus and $L$. apodus. Significant $(\mathrm{p}<0.05)$ values are highlighted in bold. + or - indicates directionality of the relationship

\begin{tabular}{|c|c|c|c|c|c|c|}
\hline \multirow{2}{*}{$\begin{array}{l}\text { Seascape } \\
\text { variable }\end{array}$} & \multicolumn{3}{|c|}{ - H. sciurus } & \multicolumn{3}{|c|}{ L. apodus } \\
\hline & $\mathrm{R}^{2}$ & $\mathrm{p}$ & Relationship & $\mathrm{R}^{2}$ & $\mathrm{p} \quad \mathrm{R}$ & Relationship \\
\hline \multicolumn{7}{|l|}{ Total edge } \\
\hline Day + Night & 0.79 & 0.0006 & - & 0.78 & 0.0002 & - \\
\hline Day & 0.67 & 0.0916 & - & 0.62 & 0.0627 & - \\
\hline Night & 0.76 & 0.0527 & - & 0.51 & 0.11 & - \\
\hline \multicolumn{7}{|l|}{ CWED } \\
\hline Day + Night & 0.16 & 0.2488 & - & 0.03 & 0.5756 & - \\
\hline Day & 0.03 & 0.7889 & + & 0.16 & 0.4288 & - \\
\hline Night & 0.01 & 0.8912 & - & 0.36 & 0.2044 & + \\
\hline \multicolumn{7}{|l|}{ Hard bottom } \\
\hline Day + Night & 0.81 & 0.0004 & - & 0.72 & 0.0005 & - \\
\hline Day & 0.63 & 0.1111 & - & 0.63 & 0.0594 & - \\
\hline Night & 0.69 & 0.0794 & - & 0.57 & 0.0843 & - \\
\hline \multicolumn{7}{|l|}{ Sand bottom } \\
\hline Day + Night & 0.75 & 0.0012 & - & 0.60 & 0.0030 & - \\
\hline Day & 0.30 & 0.3369 & - & 0.45 & 0.1466 & - \\
\hline Night & 0.88 & 0.0184 & - & 0.20 & 0.3703 & - \\
\hline \multicolumn{7}{|l|}{ Patch richness } \\
\hline Day + Night & 0.42 & 0.0426 & - & 0.31 & 0.0594 & - \\
\hline Day & 0.24 & 0.3984 & + & 0.08 & 0.5946 & - \\
\hline Night & 0.60 & 0.1264 & - & 0.32 & 0.2377 & - \\
\hline
\end{tabular}

Cocheret de la Morinière et al. 2003a,b). Clearly the juxtaposition of hard- and softbottom patch types is important in defining suitable seascapes for $H$. sciurus. Our seascape ecology approach, however, also revealed that hardbottom areas such as colonized bedrock are important for $H$. sciurus at night. In con- trast, L. apodus spent only a small proportion of its time over seagrasses compared to $H$. sciurus and instead demonstrated a clear preference for hardbottom and unvegetated sand during nocturnal periods. Further studies are required to determine whether this observed pattern reflects habitat requirements that are affected by the close proximity to higher relief areas that provide greater refuge from predators, or whether this is inter-species habitat partitioning due to competition or differences in diet (Gladfelter \& Johnson 1983, Burke 1995).

Dietary analysis indicates that Haemulon sciurus feeds primarily on benthic crustaceans and mollusks including shrimps, small portunid and xanthid crabs, and bivalve mollusks abundant in seagrass beds (Randall 1967). Nagelkerken et al. (2000) found that densities of macro-invertebrate prey (i.e. Tanaidacea and Copepoda) most commonly consumed by $H$. sciurus were higher in seagrass and algal beds than in other biotopes, which may explain $H$. sciurus showing higher residence times in soft sediment habitats. Higher residence time over hardbottom and sand patches for large, reef-dwelling Lutjanus apodus may be directly attributable to their preference for small demersal fishes (Rooker 1995, Cocheret de la Morinière et al. 2003a,b), particularly juvenile scarids and acanthurids, which are known to heavily graze areas immediately adjacent to reefs (Randall 1965). Our findings revealed that diel space use patterns are more spatially complex and variable than was previously known, since some fish use a wide range of patch types during the day and night and do not always migrate directly between resting and foraging activity spaces at sunset and sunrise. Nocturnal foraging in seagrass beds, therefore, may be a facultative behavior for some individuals and species, particularly L. apodus, which may be more generalist than $H$. sciurus (Verweij et al. 2006). Nagelkerken et al. (2000) suggested that intraspecific competition and evasion of predators may lead to inclusion of some patch types that are sub-optimal foraging areas, but offer higher refuge function.

Our results are likely to be location specific, but the high variability between sites and within species highlights the need for further tracking studies that explore geographical variability, as well as inter-species variability in seascape utilization patterns. Acoustic tracking studies are capable of revealing the detailed spatial movements that when combined with benthic habitat maps will provide more complete information on habitat utilization patterns. 
Very little is known about the development of specialized movement tactics when fish navigate across spatially heterogeneous seascapes; this presents a new frontier in behavioral landscape ecology.

\section{Path complexity and seascape structure}

Daytime movement paths were significantly more tortuous than nocturnal paths for both species. The highly convoluted, back and forth movements, often resulting in relatively small activity spaces, are indicative of sheltering behavior (Turchin 1996, Nams \& Bourgeois 2004). Unexpectedly, both species exhibited a less complex movement pathway over more spatially heterogeneous seascapes as evidenced by highly negative correlations between the fractal dimension of the pathway and seascape characteristics, such as total edge and patch richness. However, the strongest negative relationship was modeled for Haemulon sciurus nighttime path complexity and area of sand, which could be due to more directed linear movements over open sandy areas with low refuge function and low prey abundance. Further studies are required to examine foraging behavior and prey distribution throughout activity spaces. These findings provide insight into the complex movement ecology of these 2 species. Our counter-intuitive finding that movement paths were more complex in more homogeneous seascapes may be influenced by our focus on 2-dimensional structure. Future studies should also include structural characteristics of the 3-dimensional seafloor terrain that would quantify vertical relief, an important variable determining the refuge function of the seascape. Boat-based acoustic surveys or airborne hydrographic light detection and ranging (LiDAR) are capable of mapping detailed seafloor bathymetry within fish activity spaces to provide 3-dimensional terrain models of the seascape (Costa et al. 2009). Since the nocturnal activity spaces were more heterogeneous, adopting less tortuous (straighter) movements may increase the likelihood of fish encountering desired patches of food (Zollner \& Lima 1999). In controlled experimental microlandscapes, McIntyre \& Wiens (1999) manipulated the spatial arrangement of resource patches and observed low $D$ values for the movement paths of a terrestrial beetle, Eleodes extricata, when resource patches were randomly distributed. Experiments with controlled microseascapes, analogous to microlandscapes (Wiens et al. 1995), could be used to further examine the influence of seascape patterning on faunal behavioral decisions, understand navigational strategies across seascapes with different patterning, and identify structure-function threshold effects. H. sciurus and Lutjanus apodus were also observed making rapid, directed linear movements during twilight migrations, a strategy thought to reduce predation risk by minimizing the time spent in unfavorable patch types (Zollner \& Lima 1999). During these movements, a few successive detections were recorded (difficult to obtain due to the speed of movement, Figs. 2 \& 3) within sand corridors between habitat types or along the edges of reefs, indicating that the fish used edge features as easily navigable corridors between day and night activity spaces. Very little is known about the mechanisms associated with edge permeability and attraction of fish to edges, although edge effects have been reported for marine fish and invertebrates (Boström et al. 2006).

\section{Relevance of seascape types}

High variability in seascape structure across day and night activity spaces resulted in relatively low dissimilarity between groups, particularly for Lutjanus apodus. The fact that $L$. apodus seascapes for day and night activity spaces were structurally more similar to each other than were day and night spaces for Haemulon sciurus suggests that the 2 species differ in the way that they differentiate when selecting habitat, but that the selection is unlikely to be a random one. Although both species are widespread and known to utilize a wide range of patch types, it appears that $L$. apodus may be more of a seascape generalist than $H$. sciurus, which showed a distinctive twilight migration to locate softbottom areas with seagrasses for nocturnal foraging. Statistical identification of seascape types as an approach for characterizing suitable habitat can be applied as a cost-effective tool to identify beneficial combinations or configurations of patch types. This technique is also useful for classifying the relative position of fish species along a gradient of seascape generalist to specialist. It is likely that the seascape type approach may prove more discriminatory when applied to seascape specialists.

Furthermore, the inshore-offshore ontogenetic habitat shifts from embayment nurseries to non-bay coral reefs reported for grunts and snappers elsewhere in the Caribbean (Verweij \& Nagelkerken 2007, Grol et al. 2011) may not be typical. Instead, we propose that in some bays where coral reefs and seagrasses exist in close proximity, individuals that require both resources may simply expand their home range with maturity rather than shifting to deeper non-bay coral reefs.

\section{Management implications and further studies}

This study demonstrates ecological connectivity between mosaics of different patch types and highlights 
that multiple resources are important to fish at the scale of hundreds of meters. Although the level of dependence on each component patch types is unknown for many species, it is clear that to address habitat conservation for the species studied here, decision makers must consider the functional integrity of seascapes rather than focusing primarily on individual patch types. Although Haemulon sciurus and Lutjanus apodus are commonly referred to as coral reef fish, it is apparent that much of their time is spent in non-reef patch types, and the juxtaposition of both hard- and softbottom patch types combines to define suitable seascape types for the persistence of species. This information can be used to parameterize species distribution models to predict suitable areas and therefore to map essential fish habitat (EFH). This task is made more complicated by strong intra-population space use variability, but consideration of individualistic responses may be necessary to accurately map the potentially broad spectrum of patch types used by species, particularly those that appear to be seascape generalists. Consequently, our sample size of 6 individuals per species may have been insufficient to completely characterize what may be a very diverse set of routine movement patterns. We strongly advocate that more fish-habitat use studies be conducted over the daily home range extent and over multiple days for individual fish; this is particularly important when research is used to identify EFH.

For the short duration of our study, we found relatively high site fidelity within daily activity spaces that could be easily protected by fairly small marine protected areas, although protecting the life stages through ontogenetic shifts and migration to potential spawning aggregation sites for these species is likely to require larger protected areas. The movement data can be used to understand the spatial scales of nutrient and trophic fluxes occurring between day resting areas and night feeding areas. Further studies are required to determine the thresholds in seascape configuration that make some areas unsuitable or sub-optimal and others suitable. Some seascapes will enhance connectivity, growth, and survival, and the identification of these optimal seascapes is a valuable tool for marine management and particularly important for biodiversity conservation and for protection of endangered species. More detailed studies coupling high-resolution tracking with high-resolution seafloor mapping can be used to understand the behavioral response to structural features including the use of landmarks, provide insights on fish navigation, and to identify and predict migration pathways. Incorporating information on spatial patterns of food availability and foraging rates together with observations of predator and competitor interactions will link key ecological processes to seascape structure. More broadly, the spatially-explicit understanding of movement ecology is essential to guiding scale selection in ecological studies and for the development of a mechanistic foundation for seascape ecology analogous to key early development in terrestrial landscape ecology (Ims 1995, Wiens 1995, Lima \& Zollner 1996).

Acknowledgements. This research was supported by a NOAA cooperative agreement with the University of the Virgin Islands. We thank the staff of the Biogeography Branch and M. Monaco at NOAA's Center for Coastal Monitoring and Assessment for providing tracking equipment and technical support; J. Blondeau of the Center for Marine and Environmental Studies for GIS assistance; the US National Park Service for permission to operate within the St. John National Park; and H. Hitt and UVI volunteers who assisted with fish tracking. We also extend our gratitude to 4 anonymous reviewers for extensive comments that helped in the refinement of this manuscript. This is contribution no. 62 from University of the Virgin Islands' Center for Marine and Environmental Studies.

\section{LITERATURE CITED}

Addicott JF, Aho JM, Antolin MF, Padilla DK, Richardson JS, Soluk DA (1987) Ecological neighborhoods: scaling environmental patterns. Oikos 49:340-346

> Beets J, Friedlander A (1998) Evaluation of a conservation strategy: a spawning aggregation closure for red hind, Epinephelus guttatus, in the U.S. Virgin Islands. Environ Biol Fishes 55:91-98

Beets J, Muehlstein L, Haught K, Schmitges H (2003) Habitat connectivity in coastal environments: patterns and movements of Caribbean coral reef fishes with emphasis on bluestriped grunt, Haemulon sciurus. Gulf Caribb Res 14: $29-42$

Bolnick DI, Svanbäck R, Fordyce JA, Yang LH, Davis JM, Hulsey CD, Forister ML (2003) The ecology of individuals: incidence and implications of individual specialization. Am Nat 161:1-28

Boström C, Jackson EL, Simenstad CA (2006) Seagrass landscapes and their effects on associated fauna: a review. Estuar Coast Shelf Sci 68:383-403

- Boström C, Pittman SJ, Simenstad C, Kneib RT (2011) Seascape ecology of coastal biogenic habitats: advances, gaps, challenges. Mar Ecol Prog Ser 427:191-217

Burke NC (1995) Nocturnal foraging habitats of French and bluestriped grunts, Haemulon flavolineatum and H. sciurus, at Tobacco Caye, Belize. Environ Biol Fishes 42:365-374

> Chapman MR, Kramer DL (2000) Movements of fishes within and among fringing coral reefs in Barbados. Environ Biol Fishes 57:11-24

Clark RD, Pittman SJ, Caldow C, Christensen J, Roque B, Appeldoorn RS, Monaco ME (2009) Nocturnal fish movement and trophic flow across habitat boundaries in a coral reef ecosystem (SW Puerto Rico). Caribb J Sci 45:282-303

> Clarke KR (1993) Non-parametric multivariate analyses of change in community structure. Aust J Ecol 18:117-143

Clarke KR, Gorley RN (2006) PRIMER v6: user manual/ tutorial. PRIMER-E Ltd, Plymouth

Clarke KR, Green RH (1988) Statistical design and analysis for a 'biological effects' study. Mar Ecol Prog Ser 46: $213-226$ 
Clarke KR, Somerfield PJ, Chapman MG (2006) On resemblance measures for ecological studies, including taxonomic dissimilarities and a zero-adjusted Bray-Curtis coefficient for denuded assemblages. J Exp Mar Biol Ecol 330:55-80

Cocheret de la Morinière E, Pollux BJA, Nagelkerken I, Hemminga MA, Huiskes AHL, van der Velde G (2003a) Ontogenetic dietary changes of coral reef fishes in the mangrove-seagrass-reef continuum: stable isotopes and gut-content analysis. Mar Ecol Prog Ser 246:279-289

Cocheret de la Morinière E, Pollux BJA, Nagelkerken I, van der Velde G (2003b) Diet shifts of Caribbean grunts (Haemulidae) and snappers (Lutjanidae) and the relation with nursery-to-coral reef migrations. Estuar Coast Shelf Sci 57:1079-1089

> Costa BM, Battista TA, Pittman SJ (2009) Comparative evaluation of airborne LiDAR and ship-based multibeam SoNAR bathymetry and intensity for mapping coral reef ecosystems. Remote Sens Environ 113:1082-1100

Dahlgren CP, Eggleston DB (2000) Ecological processes underlying ontogenetic habitat shifts in a coral reef fish. Ecology 81:2227-2240

> Dorenbosch M, Verweij MC, Nagelkerken I, Jiddawi N, van der Velde G (2004) Homing and daytime tidal movements of juvenile snappers (Lutjanidae) between shallow-water nursery habitats in Zanzibar, western Indian Ocean. Environ Biol Fishes 70:203-209

Elkie P, Rempel R, Carr A (1999) Patch analyst user's manual. Ontario Ministry of Natural Resources Northwest Science \& Technology. TM-002. Thunder Bay, ON

Friedlander AM, Parrish JD (1998) Temporal dynamics of fish communities on an exposed shoreline in Hawaii. Environ Biol Fishes 53:1-18

Gillanders BM, Able KW, Brown JA, Eggleston DB, Sheridan PF (2003) Evidence of connectivity between juvenile and adult habitats for mobile marine fauna: an important component of nurseries. Mar Ecol Prog Ser 247:281-295

Gladfelter WB, Johnson WS (1983) Feeding niche separation in a guild of tropical reef fishes (Holocentridae). Ecology 64:552-563

Grober-Dunsmore R, Pittman SJ, Caldow C, Kendall MA, Fraser T (2009) A landscape ecology approach for the study of ecological connectivity across tropical marine seascapes. In: Nagelkerken I (ed) Ecological connectivity among tropical coastal ecosystems. Springer, New York, NY, p 493-530

Grol MGG, Nagelkerken I, Rypel AL, Layman CA (2011) Simple ecological trade-offs give rise to emergent crossecosystem distributions of a coral reef fish. Oecologia 165:79-88

Halpin PM (2000) Habitat use by an intertidal salt-marsh fish: trade-offs between predation and growth. Mar Ecol Prog Ser 198:203-214

Hammerschlag N, Serafy JE (2010) Nocturnal fish utilization of a subtropical mangrove-seagrass ecotone. PSZN I: Mar Ecol 31:364-374

> Hammerschlag N, Heithaus MR, Serafy JE (2010) Influence of predation risk and food supply on nocturnal fish foraging distributions along a mangrove-seagrass ecotone. Mar Ecol Prog Ser 414:223-235

> Hammerschlag-Peyer CM, Layman CA (2010) Intrapopulation variation in habitat use by two abundant coastal fish species. Mar Ecol Prog Ser 415:211-220

> Holland KN, Lowe CG, Wetherbee BM (1996) Movements and dispersal patterns of blue trevally (Caranx melampygus) in a fisheries conservation zone. Fish Res 25:279-292 Ims RA (1995) Movement patterns related to spatial struc- tures. In: Hansson L, Fahrig L, Meriam G (eds) Mosaic landscapes and ecological processes. Chapman \& Hall, London, p 85-109

Irlandi EA, Crawford MK (1997) Habitat linkages: the effect of intertidal saltmarshes and adjacent subtidal habitats on abundance, movement, and growth of an estuarine fish. Oecologia 110:222-230

Kendall M, Miller T (2008) The influence of thematic and spatial resolution on maps of a coral reef ecosystem. Mar Geod 31:75-102

Kendall MS, Monaco ME, Buja KR, Christensen JD, Kruer CR, Finkbeiner M, Warner RA (2001) Methods used to map the benthic habitats of Puerto Rico and the U.S. Virgin Islands. Available at http://ccma.nos.noaa.gov/products/ biogeography/digitizer/welcome.html

Kendall MS, Miller TJ, Pittman SJ (2011) Patterns of scaledependency and the influence of map resolution on the seascape ecology of reef fish. Mar Ecol Prog Ser 427: 259-274

Kieckbusch DK, Koch MS, Serafy JE, Anderson WT (2004) Trophic linkages among primary producers and consumers in fringing mangroves of subtropical lagoons. Bull Mar Sci 74:271-285

Krumme U (2009) Diel and tidal movements by fish and decapods linking tropical coastal ecosystems. In: Nagelkerken I (ed) Ecological connectivity among tropical coastal ecosystems. Springer, New York, NY, p 271-324

Laver P (2005) ABODE: kernel home range estimation for ArcGIS, using VBA and ArcObjects. User manual (Beta v. 2-7). Available at http://filebox.vt.edu/users/plaver/ abode/home.html

Layman CA, Allgeier JE, Rosemond AD, Dahlgren CP, Yeager LA (2011) Marine fisheries declines viewed upside down: human impacts on consumer-driven nutrient recycling. Ecol Appl 21:343-349

> Lima SL, Zollner PA (1996) Towards a behavioral ecology of ecological landscapes. Trends Ecol Evol 11:131-135

- Lowe CG, Topping DT, Cartamil DP, Papastamatiou YP (2003) Movement patterns, home range, and habitat utilization of adult kelp bass Paralabrax clathratus in a temperate notake marine reserve. Mar Ecol Prog Ser 256:205-216

Ma Z, Redmond RL (1995) Tau coefficients for accuracy assessment of classification of remote sensing data. Photogramm Eng Remote Sens 61:435-439

McFarland WN, Ogden JC, Lythgoe JN (1979) The influence of light on the twilight migrations of grunts. Environ Biol Fishes 4:9-22

McGarigal K, Cushman SA, Neel MC, Ene E (2002) FRAGSTATS: spatial pattern analysis program for categorical maps. University of Massachusetts, Amherst, MA. Available at www.umass.edu/landeco/research/fragstats/ fragstats.html

McIntyre NE, Wiens JA (1999) Interactions between landscape structure and animal behavior: the roles of heterogeneously distributed resources and food deprivation on movement patterns. Landsc Ecol 14:437-447

Menza C (2008) Sampling design tool for ArcGIS. Biogeography Branch, NOAA Center for Coastal Monitoring and Assessment (CCMA). Available at http://ccma.nos.noaa.gov/ products/biogeography/sampling (accessed 31/05/2010)

> Meyer JL, Schultz ET (1985) Migrating haemulid fishes as a source of nutrients and organic matter on coral reefs. Limnol Oceanogr 30:146-156

> Meyer JL, Schultz ET, Helfman GS (1983) Fish schools: an asset to corals. Science 220:1047-1049

- Mumby PJ, Edwards AJ, Arias-Gonzalez JE, Lindeman KC and others (2004) Mangroves enhance the biomass of 
coral reef fish communities in the Caribbean. Nature 427:533-536

Nagelkerken I, van der Velde G (2004) Relative importance of interlinked mangroves and seagrass beds as feeding habitats for juvenile reef fish on a Caribbean island. Mar Ecol Prog Ser 274:153-159

Nagelkerken I, Dorenbosch M, Verberk WCEP, Cocheret de la Morinière E, van der Velde G (2000) Day-night shifts of fishes between shallow-water biotopes of a Caribbean bay, with emphasis on the nocturnal feeding of Haemulidae and Lutjanidae. Mar Ecol Prog Ser 194: $55-64$

> Nams VO (2005) Using animal movement paths to measure response to spatial scale. Oecologia 143:179-188

Nams VO, Bourgeois M (2004) Fractal analysis measures habitat use at different spatial scales: an example with American marten. Can J Zool 82:1738-1747

Ogden JC, Buckman NS (1973) Movements, foraging groups, and diurnal migrations of the striped parrotfish Scarus croicensis Bloch (Scaridae). Ecology 54:589-596

Ogden JC, Ehrlich PR (1977) The behavior of heterotypic resting schools of juvenile grunts (Pomadasyidae). Mar Biol 42:273-280

Papastamatiou YP, Lowe CG, Caselle JE, Friedlander AM (2009) Scale-dependent effects of habitat on movements and path structure of reef sharks at a predator-dominated atoll. Ecology 90:996-1008

Parrish JD (1989) Fish communities of interacting shallowwater habitats in tropical oceanic regions. Mar Ecol Prog Ser 58:143-160

Pittman SJ, McAlpine CA (2003) Movement of marine fish and decapod crustaceans: process, theory and application. Adv Mar Biol 44:205-294

Pittman SJ, McAlpine CA, Pittman KM (2004) Linking fish and prawns to their environment: a hierarchical landscape approach. Mar Ecol Prog Ser 283:233-254

Pittman SJ, Caldow C, Hile SD, Monaco ME (2007) Using seascape types to explain the spatial patterns of fish in the mangroves of SW Puerto Rico. Mar Ecol Prog Ser 348: $273-284$

Submitted: June 3, 2010; Accepted: February 18, 2011
Randall JE (1965) Grazing effect on sea grasses by herbivorous reef fishes in the West Indies. Ecology 46:255-260

Randall JE (1967) Food habits of reef fishes of the West Indies, Institute of Marine Biology, University of Puerto Rico, Mayaguez

> Robbins BD, Bell SS (1994) Seagrass landscapes: a terrestrial approach to the marine subtidal environment. Trends Ecol Evol 9:301-304

Rooker JR (1995) Feeding ecology of the schoolmaster snapper, Lutjanus apodus (Walbaum), from southwestern Puerto Rico. Bull Mar Sci 56:881-894

Rooker JR, Dennis GD (1991) Diel, lunar and seasonal changes in a mangrove fish assemblage off southwestern Puerto Rico. Bull Mar Sci 49:684-698

Tolimieri N, Andrews K, Williams G, Katz S, Levin PS (2009) Home range size and patterns of space use by lingcod, copper rockfish and quillback rockfish in relation to diel and tidal cycles. Mar Ecol Prog Ser 380:229-243

Topping DT, Lowe CG, Caselle JE (2005) Home range and habitat utilization of adult California sheephead, Semicossyphus pulcher (Labridae), in a temperate no-take marine reserve. Mar Biol 147:301-311

> Turchin P (1996) Fractal analyses of animal movement: a critique. Ecology 77:2086-2090

- Verweij MC, Nagelkerken I (2007) Short and long-term movement and site fidelity of juvenile Haemulidae in back-reef habitats of a Caribbean embayment. Hydrobiologia 592:257-270

> Verweij MC, Nagelkerken I, Wartenbergh SLJ, Pen IR, van der Velde G (2006) Caribbean mangroves and seagrass beds as daytime feeding habitats for juvenile French grunts, Haemulon flavolineatum. Mar Biol 149:1291-1299

Wiens JA (1995) Landscape mosaics and ecological theory. In: Hansson L, Fahrig L, Meriam G (eds) Mosaic landscapes and ecological processes. Chapman \& Hall, London

> Wiens JA, Crist TO, With KA, Milne BT (1995) Fractal patterns of insect movement in microlandscape mosaics. Ecology 76:663-666

- Zollner PA, Lima SL (1999) Search strategies for landscapelevel interpatch movements. Ecology 80:1019-1030

Proofs received from author(s): April 2, 2011 